\title{
The atraumatic restorative treatment approach: An "atraumatic" alternative
}

\author{
Thiago-Saads Carvalho ${ }^{1}$, Talitha-Rodrigues Ribeiro ${ }^{2}$, Marcelo Bönecker ${ }^{3}$, Elayne-Cristina-Morais Pinheiro ${ }^{4}$, \\ Viviane Colares ${ }^{5}$
}

${ }^{1}$ DDS, MS. Universidade de São Paulo

${ }^{2}$ DDS, MS. Universidade Federal da Paraíba

${ }^{3}$ DDS, MS, PhD, Assistant Professor. Universidade de São Paulo

${ }^{4}$ PSYD. Universidade Federal de São Paulo

${ }^{5}$ DDS, MS, PhD, Assistant Professor. Universidade de Pernambuco

Correspondence:

Departamento de Odontopediatria

Faculdade de Odontologia

Universidade de São Paulo

Avenida Professor Lineu Prestes, 2227

Cidade Universitária,

CEP. 05508-000

São Paulo-SP, Brazil

thiagosaads@hotmail.com

Received: $24 / 02 / 2009$

Accepted: 08/06/2009
Carvalho TS, Ribeiro TR, Bönecker M, Pinheiro ECM, Colares V. The atraumatic restorative treatment approach: An "atraumatic" alternative. Med Oral Patol Oral Cir Bucal. 2009 Dec 1;14 (12):e668-73. http://www.medicinaoral.com/medoralfree01/v14i12/medoralv14i12p668.pdf

\section{Article Number: $2719 \quad$ http://www.medicinaoral.com/}

(C) Medicina Oral S. L. C.I.F. B 96689336 - pISSN 1698-4447 - eISSN: $1698-6946$

eMail: medicina@medicinaoral.com

Indexed in:

-SCI EXPANDED

-JOURNAL CITATION REPORTS

-Index Medicus / MEDLINE / PubMed

-EMBASE, Excerpta Medica

-SCOPUS

-Indice Médico Español

\begin{abstract}
Introduction: Fear and anxiety are part of all human experiences and they may contribute directly to a patient's behavior. The Atraumatic Restorative Treatment (ART) is a technique that may be an alternative approach in treating special care patients or those who suffer fear or anxiety. Objective: the aim of this paper is to review the ART technique as an alternative to reduce pain and fear during dental treatment. Materials and method: A search for the term "atraumatic restorative treatment" was carried out in the MEDLINE search engine. References, from the last 10 years, containing at least one of the terms: "psychological aspects", "discomfort", "fear", "anxiety" or "pain", were selected.

Results: A total of 120 references were found, from which only 17 fit the criteria. Discussion: All authors agreed that the ART promotes less discomfort for patients, contributing to a reduction of anxiety and fear during the dental treatment. Results also indicated that ART minimizes pain reported by patients. Conclusions: The ART approach can be considered as having favorable characteristics for the patient, promoting an "atraumatic" treatment. This technique may be indicated for patients who suffer from fear or anxiety towards dental treatments and whose behavior may cause the treatment to become unfeasible or even impossible altogether.
\end{abstract}

Key words: Atraumatic restorative treatment, discomfort, fear, anxiety, pain.

\section{Introduction}

The Atraumatic Restaurative Treatment (ART) was initially developed for the promotion of oral health in communities with lower socioeconomic status who live in remote areas of developing countries, where dental treatment is not readily available. However, due to its "atraumatic" approach, this technique may be an alter- native approach to treat patients, as it uses manual instruments and glass ionomer cements. Similarly to the conventional caries treatment using the bur, the ART approach also prevents further removal of healthy tissues (1).

Although the ART approach was originally not readily 
accepted by some dental associations, nowadays such a technique is accepted in developed countries (2), and it may be carried out on patients who suffer from fear of the dental treatment (1). It has been observed that $9 \%$ of children and adolescents may suffer from dental fear or need special behavioral management (3).

Fear is an inherent part of human development, and is an adaptive response of the body for imminent risk. Its absence, or its exaggerated presence, is alarming, as it may be a sign of pathology. Anxiety, on the other hand, is an emotional state present in all human experiences. It has physiological and psychological aspects, and it contributes directly to the individual's behavior. Pathological anxiety is an overly expressed state of fear, which leads to increased vigilance and excitability. These psychological, behavioral and cognitive reactions may be pathological and they are not always easy for the dentist to differentiate them (4).

In relation to dental treatment, fear is frequently related to the patient's age, general emotional state, and the subjective experience to pain or trauma. In adult patients, fear and anxiety have been researched through stress levels. It has been stated that the prevalence of stress in such patients was as high as $96 \%$, and that very high levels of stress was present in $10 \%$ of adult patients. Some factors, such as gender, where the patient lives and the presence of an accompanying person were related to the high levels of stress (5). When dealing with children, fear could also be related to the mother's fear to dental treatment. However, anxiety may be related to a generalized behavioral reaction of the patient.

Some studies have been carried out regarding the "atraumatic" perceptive of the ART approach, especially in relation to stress and pain experienced by patients during dental treatment. Pain and discomfort were most frequently observed in conventional restorations when rotary instruments were used, than when manual instruments were used, as recommended by the ART approach. Such discomfort could mainly be related to the restorative technique, the operator, or the patient's age and gender (6-8).

Due these "atraumatic" aspects, the ART approach may be a very useful tool when treating some patients, such as when treating high caries risk patients, children and disadvantaged patients, such as special care patients, the elderly and those who have experienced discomfort, anxiety or pain (1).

Therefore, the aim of this paper is to review the ART technique as an alternative to reduce pain and fear during dental treatment.

\section{Materials and Method}

The authors used the term "atraumatic restorative treatment" to carrie out a search in MEDLINE. The selection criteria for the abstracts were: (a) references in Eng- lish, Spanish or Portuguese, (b) published in the last 10 years, and (c) containing at least one of the terms: "psychological aspects", "discomfort", "fear", "anxiety" or "pain".

One hundred and twenty references were found in MEDLINE, using the term atraumatic restorative treatment. Amongst the references found, a total of 17 were selected: 4 were review of literature and 13 were research studies $(1,3,6-20)$. The 13 research studies are summarized in Table 1.

\section{Results}

The 17 research studies selected had samples including children or teenagers from Central and South America, Africa and Asia, but only one of the studies had adult patients in its sample.

Lo and Holmgren (9) carried out a study in 95 Chinese children, aged between 5 and 6 years, performing a total of 170 ART restorations in primary teeth. A great number of children $(93 \%)$ reported no discomfort or pain during the dental treatment, and $86 \%$ accepted the ART technique and would undergo dental treatment once again. The authors concluded that the ART approach was highly accepted by children (9). This could be due to the lesser pain sensation experienced by the children who undergo the atraumatic restorative treatment (10). One other study assessing how children and teenagers accept the ART approach had a sample of 118 patients, aged 5 to 18 years, from a community near Mexico City. The restorations and sealants were performed using the ART approach, and a great deal of children reported no pain during caries removal $(68 \%)$ and during filling of the cavity (85\%). Also, $93 \%$ of the patients were satisfied with the restorations (11).

Studies that compared both kinds of treatment (ART and minimal invasive treatment using rotary instruments) observed that restorations carried out using the ART approach cause less pain to the patient.

When treated with the ART approach, $26 \%$ of patients reported pain, whereas a significantly greater proportion reported pain when minimal invasive restoration was carried out using the bur (7). In the study by van Amerongen and Rahimtoola (6), twice as many patients treated by rotary instruments reported pain when compared to those treated by ART. The same study showed that pain reports were not only related to the restorative technique, but also to the operator. The influence of the operator in achieving a better behavior in patients undergoing dental treatments was also emphasized by Deery (12).

Additionally, ART was compared to Minimum Intervention Treatment (MIT) in 401 schoolchildren, between 6 and 9 years old, in South Africa (13). When the patients' primary teeth were treated, a pain assessment showed that $80 \%$ of the children experienced no pain, 


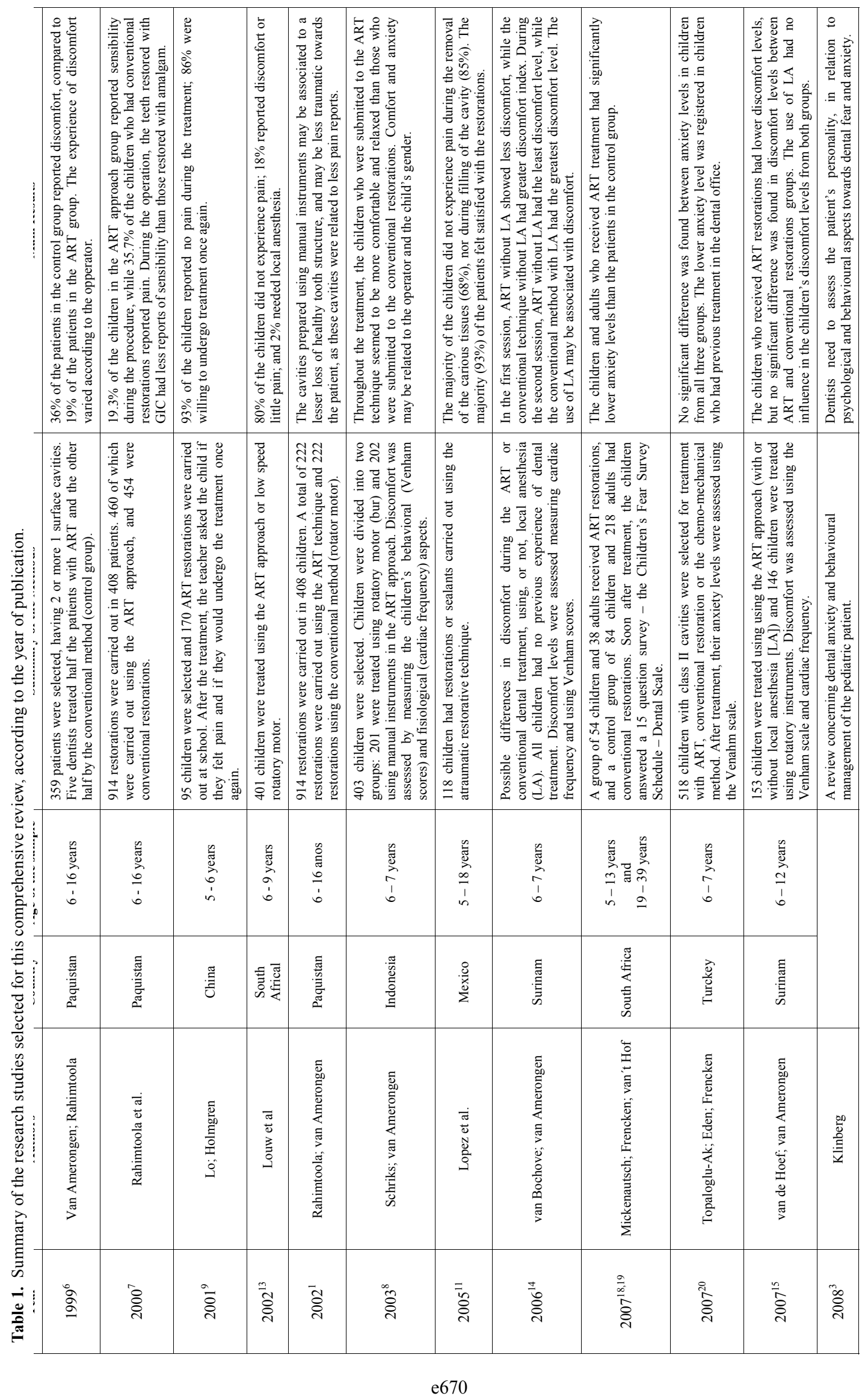


$18 \%$ experienced mild discomfort or little pain, and local anesthesia was necessary in $2 \%$ of the children.

Some studies have used the modified Venham index to monitor the chilldren's psychological aspects after dental treatment. This scale is based on a 6-point scale, ranging from 0 to 5, representing the children's behavior during the dental treatment. This scale best describe the children's feeling towards the treatment (8).

When psychological and physiological aspects were monitored, by the Venham scale and cardiac frequency, during two kinds of treatment (ART and conventional treatment), the ART technique was observed to be less stressing for the patient. Although no significant difference was observed between cardiac frequencies in children from both groups, the Venham scores showed that patients treated by the ART approach were more comfortable than the patients treated by the conventional approach. So, the authors suggested that the anxiety present in some children undergoing dental treatment might by associated to the needle during anesthesia or the motor of the rotary instrument (8).

In order to investigate discomfort caused either by infiltrative local anesthesia or the treatment approach, van Bochove and van Amerongen (14) (2006) investigated discomfort, using the Venham Score and cardiac frequency, in 6 to 7 year olds with no prior dental treatment experience. The children were treated by ART or by the conventional technique, with or without local anesthesia (LA). The study showed that during the first dental treatment session ART with no LA caused less discomfort, whereas conventional treatment with no LA caused a greater degree of discomfort. However, during the second dental treatment session, ART with no LA also caused less discomfort, but the conventional treatment with LA caused a greater discomfort. Therefore, the authors concluded that the use of LA may be associated to the discomfort experienced by children during dental treatment.

In one other study, no significant difference in discomfort was observed when children were treated by ART or the conventional techniques. However, children treated by the ART approach demonstrated lower discomfort levels and the use of local anesthesia did not influence the degree of discomfort (15).

From all selected references, two related significant correlation between the size of the dental cavity and the experience of pain. Patients with bigger cavity preparations, treated with either ART or the conventional techniques, reported pain most frequently. However, cavities prepared by the ART approach are significantly smaller than those prepared by rotary instruments $(1,6)$.

When treating children, various different strategies are adopted in order to achieve the patient's cooperation, such as behavioral control or the use of sedation. However, the maintenance of the patient's behavior is directly related to the comfort and the time taken in the treatment. These factors are directly related to the ART approach, as it is a simple technique which uses glass ionomer cements, which require minimum cavity preparation, it is easy to apply and it has chemical adhesion to the dental tissues (16).

Mickenautsch and Rudolph (17) (2001) reported the importance of ART implementation in the public services in South Africa as a way to promote an appropriate and economic dental treatment to inaccessible populations. The authors considered relevant its "less traumatic" aspect, especially for children who suffer from fear of dental treatment. In South Africa, children and adults, who were submitted to the atraumatic restorative treatment, showed significantly lower levels of anxiety than individuals who underwent conventional treatment $(18,19)$.

Furthermore, when 518 children who needed class II restorations were treated by three kinds of caries removal method (traditional, ART and chemical-mechanic methods), no significant differences were found in the anxiety levels between the groups. However, the study showed that children who had previous contact with the dental office environment had lower anxiety levels. The dentist's psychological approach towards children seemed to be fundamental in succeeding with their treatment (20). Consequently, Klinberg (3) suggests that dentists should assess each patient regarding his/her psychological and personality aspects in order to further understand the individual patient.

\section{Discussion}

The term "Atraumatic Restorative Treatment" by itself suggests that the treatment may cause minimum - or no - trauma to the patient (reducing pain and discomfort) and to the tooth (conserving healthy tooth structures and reducing trauma to the pulp). Moreover, the term "atraumatic" may suggest that the technique causes "less trauma" when compared to other dental treatment techniques $(6,16)$. Although mild discomfort and minimal pain can be occasionally experienced during dental treatments, such factors might not cause psychological distress to some patients. As a result, some studies $(1,7)$ suggest that more research is necessary in relation to operative sensibility (pain during the dental treatment), as it is a main factor in determining if the patient accepts the technique.

In comparison to the conventional treatment, the ART approach causes a reduction in pain sensation which may be related to the greater preservation of the dental tissues and, consequently, the patient becomes more receptive towards the treatment (10).

Some causes for pain or anxiety in children are summarized in Table 2.

In such a view, it can be observed that the subjective 
Table 2. Summary of some possible aspects which may cause fear and anxiety in children.

\begin{tabular}{|l|c|}
\hline \multicolumn{2}{|c|}{ Some possible causes for children's fear and anxiety during treatment } \\
\hline Treatment Aspects: & The size and depth of the cavity \\
\hline & Sounds or vibrations of the instruments or bur \\
\hline Psychological Aspects: & The professional's skills in behavior management or therapeutic methods \\
\hline & The child's own psychological aspects \\
\hline & The child's own fantasies and imagination \\
\hline & Fears and anxiety previous to the treatment \\
\hline & Uncomfortable experiences related as pain \\
\hline
\end{tabular}

perspective of pain should also be considered during such studies, as children may indicate any kind of discomfort or unpleasurable experience as "pain" (7). Therefore, any sound or vibration during the dental treatment, caused by the bur or manual instruments, could be considered as discomfort to the child, resulting in a report of pain. The sensation of discomfort during some procedures in the dental clinic triggers fantasies in the child's imagination, causing fear and anxiety during dental treatment. For such reason, the dentist's constant intercession with the patient is extremely important during the dental treatment, especially when treating a child (3). This intercession, through clear explanations and talks, promotes the child's adaptation to the dental clinic environment, thus modifying the child's attitudes, fears and anxiety. Also, the dentist should be aware to individual fears and anxieties their child patients may have before and during the dental treatments, thus reducing non-cooperative behaviors (3).

Focusing on the psychological point of view, the professional may use the ART approach when dealing with fearful children and those whose fantasies and imagination may cause some degree of anxiety towards the treatment. Such an approach may be less traumatic to the children, and it may positively influence the children's behavior towards future dental treatments. The professional must, however, bear in mind the constant need to talk to the child and parents to minimize uncomfortable experiences and parental influences during the treatment. From the clinical point of view, the professional may use the ART approach when treating deeper cavities. The ART approach seems to be less traumatic to the tooth, and, therefore, it is in accordance with the minimum intervention philosophy. Also, less noise and vibrations during the treatment may cause less stress for the children. Moreover, the ART approach may still be put into practice in field situations where there is a lack of electricity or dental offices, or for communities of lower socio-economic status.
In this study, we observed that all authors agreed that the ART approach is a treatment that causes less discomfort to the patient, thus contributing to the reduction of anxiety and fear during the dental treatment. Therefore, although the term "atraumatic" does not assure total absence of trauma or pain, it is in agreement with the ART approach philosophy. Hence, ART is a patient friendly technique. This technique promotes favorable characteristics in the patients' acceptance of the treatment.

\section{Conclusions}

From this comprehensive review, it can be concluded that ART is a curative method, which has favorable characteristics for patient's dental treatment. This may be either due to the use of manual instruments or because ART does not require local anesthesia. In the conventional treatment, the rotary instrument has a characteristic noise, frightening the child or triggering unpleasurable memories, thus causing discomfort. Undoubtedly, the needle used in local anesthesia also causes emotional discomfort, and eventually physical pain. Although most studies published on this topic is related to children, the ART approach uses manual instruments, which creates smaller cavities and less pain, thus giving ART its "atraumatic" characteristics. As a result, one may suggest that it is a suitable approach to be used in children, the elderly, special needs patients, or patients who demonstrate fear and anxiety towards dental treatment, and whose behavior may cause the treatment to become unfeasible or even impossible altogether. Therefore, the dentist's awareness and understanding of each patient's needs, as well as his/her intercession towards the patient, are of great importance for the success of the treatment. 


\section{References}

1. Rahimtoola S, Van Amerongen E. Comparison of two tooth-saving preparation techniques for one-surface cavities. ASDC J Dent Child. 2002;69:16-26.

2. Pilot T. Introduction--ART from a global perspective. Community Dent Oral Epidemiol. 1999;27:421-2.

3. Klinberg G. Dental anxiety and behaviour management problems in paediatric dentistry--a review of background factors and diagnostics. Eur Arch Paediatr Dent. 2008;9 Suppl 1:11-5.

4. Rosen JB, Schulkin J. From normal fear to pathological anxiety. Psychol Rev. 1998;105:325-50.

5. Rodríguez Vázquez LM, Rubiños López E, Varela Centelles A, Blanco Otero AI, Varela Otero F, Varela Centelles P. Stress amongst primary dental care patients. Med Oral Patol Oral Cir Bucal. 2008;13:E253-6.

6. Van Amerongen WE, Rahimtoola S. Is ART really atraumatic? Community Dent Oral Epidemiol. 1999;27:431-5.

7. Rahimtoola S, Van Amerongen E, Maher R, Groen H. Pain related to different ways of minimal intervention in the treatment of small caries lesions. ASDC J Dent Child. 2000;67:123-7, 83.

8. Schriks MC, van Amerongen WE. Atraumatic perspectives of ART: psychological and physiological aspects of treatment with and without rotary instruments. Community Dent Oral Epidemiol. 2003;31:15-20.

9. Lo EC, Holmgren CJ. Provision of Atraumatic Restorative Treatment (ART) restorations to Chinese pre-school children--a 30-month evaluation. Int J Paediatr Dent. 2001;11:3-10.

10. Frencken JE, Holmgren CJ. ART: A minimal intervention approach to manage dental caries. Dent Update. 2004;31:295-8, 301.

11. Lopez N, Simpser-Rafalin S, Berthold P. Atraumatic restorative treatment for prevention and treatment of caries in an underserved community. Am J Public Health. 2005;95:1338-9.

12. Deery C. Atraumatic restorative techniques could reduce discomfort in children receiving dental treatment. Evid Based Dent. 2005;6:9.

13. Louw AJ, Sarvan I, Chikte UM, Honkala E. One-year evaluation of atraumatic restorative treatment and minimum intervention techniques on primary teeth. SADJ. 2002;57:366-71.

14. van Bochove JA, van Amerongen WE. The influence of restorative treatment approaches and the use of local analgesia, on the children's discomfort. Eur Arch Paediatr Dent. 2006;7:11-6.

15. Van de Hoef N, Van Amerongen E. Influence of local anaesthesia on the quality of class II glass ionomer restorations. Int J Paediatr Dent. 2007;17:239-47.

16. Tascón J. Atraumatic restorative treatment to control dental caries: history, characteristics, and contributions of the technique. Rev Panam Salud Publica. 2005;17:110-5.

17. Mickenautsch S, Rudolph MJ. Implementation of the ART approach in South Africa: an activity report. SADJ. 2001;56:327-9.

18. Mickenautsch S, Frencken JE, van't HM. Atraumatic restorative treatment and dental anxiety in outpatients attending public oral health clinics in South Africa. J Public Health Dent. 2007;67:17984.

19. Mickenautsch S, Frencken JE, Van't Hof M. Factors inhibiting the implementation of the Atraumatic Restorative Treatment approach in public oral health services in Gauteng province, South Africa. J Appl Oral Sci. 2007;15:1-8.

20. Topaloglu-Ak A, Eden E, Frencken JE. Perceived dental anxiety among schoolchildren treated through three caries removal approaches. J Appl Oral Sci. 2007;15:235-40.

\section{Acknowledgements}

The authors would like to thank CAPES for supporting the present study. 